\section{Disposable cups have eco merit}

SIR - In order to compare the relative merits of reusable and disposable cups I have examined their respective energy costs. First, I assembled a large energy database of the component technologies required to make various cup types. Wherever feasible, this information included all aspects of the energy costs of each technology from its initial extraction from the ground or harvesting stage to the final cup product. I then selected a median energy requirement for each cup technology from these data.

I collected a range of 8-ounce cups of each type from several countries and weighed them to establish a mass range for each type. I used the cup of median mass for each cup type, which closely matched the mean for each cup type, for a detailed energy assessment. Considering only the energy cost to manufacture the cups,

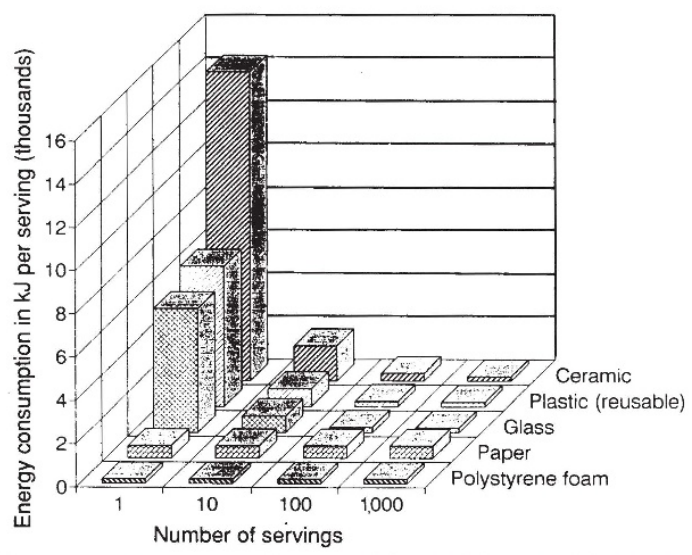

Energy consumption by reusable and disposable cups in $\mathrm{kJ}$ per serving. Assumes one use before washing for reusable cups, and one use before discard of disposable cups.

10-70 uses of a reusable cup are needed before the energy required per use comes down to the energy cost to make the disposable ones. (This comparison ignores the energy costs of cleaning and sanitizing required for commercial use of reusable cups.)

I collected information on hot water and operating energy requirements of commercial dishwashers. The electrical energy requirement range per cup per wash is $70-151 \mathrm{~kJ}$. An energy-efficient under-counter dishwasher model gave a median value for cleaning energy cost of $105.5 \mathrm{~kJ}$ of electrical energy per cup per wash. To account for the primary energy consumption required to produce this electricity, the area of operation of the dishwasher has to be specified to account for the differing efficiencies of electricity generation in different countries, for example: Canada $57.3 \%$; United Kingdom $35.2 \%$; and the United States $38.0 \%$ (refs $1,2)$. Taking the conservative Canadian generating efficiency as an example, the
$105.5 \mathrm{~kJ}$ per cup of electrical energy works out to a primary energy expenditure of 184 $\mathrm{kJ}$ per cup per wash. washing into the cup comparison energy matrix increases the number of servings required from reusable cups, before their energy costs per use come down to the energy costs of the disposables, to 15 for the glass/paper cup pair, and 1,006 for the ceramic/polystyrene foam cup pair (see figure). These values are in agreement with those obtained in other studies using different methodologies (refs 3, 4). If one considers the lower UK or US generating efficiencies, the median primary energy values required to clean and sanitize a reusable cup rise to 300 and $278 \mathrm{~kJ}$, respectively. Both these energy requirements are greater than the $198 \mathrm{~kJ}$ required to make a moulded polystyrene foam disposable cup.

To aid in the selection of appropriate cup types for different public service situations, I calculated the break-even servings required from the reusable cups to obtain a "required return rate" needed to equate in energy terms to the disposables. One serving per wash of the reusables in comparison to one serving before discard of the disposables required a return rate of $94-99.9 \%$, using the Canadian generating efficiency. Thus, the most favourable comparison for reusables would require a return of more than 94 times out of a 100 uses (without loss or discard) for them to have lower energy consumption than the disposables. The least favourable comparison for reusable cups requires over 999 returns out of 1,000 uses.

Most people prefer to use a ceramic, glass or hard plastic cup than any of the disposable varieties. For everyday use in the home or in restaurants, where a reusable cup may last 500 or more cycles, their use makes sense. But my analysis demonstrates that, from the point of view of energy conservation, there is good reason to use one of the disposable cup types when the return rate is likely to be low. If a ceramic cup is used less than 39 times it would be energy-smart to use a paper cup. The equivalent comparison for the ceramic/polystyrene foam cups would require more than 1,000 uses of the former to consume less energy per use. Of course, two or more uses of either cup type before washing (for the reusables) or discard (for the disposables) decreases the energy cost per use proportionately.

Of the disposable cups used in this analysis, the moulded polystyrene foam cup consumes the least total energy
Including the primary energy cost of per unit. The uncoated paper cup, on the other hand, consumes the least fossil-fuel energy per unit, much of the energy for production being derived from the renewable sources of wood waste, lignin and the like.

A full version of this paper, including the databases, equations, sensitivity tests, and effects of recycle options, will be published shortly in Environmental Management.

\section{Martin B. Hocking}

Department of Chemistry,

University of Victoria, Victoria,

British Columbia, Canada V8W3P6

\section{Energy Statistics of OECD Countries, 1989-1990221 (Int. Energy Agency, OECD, Paris, 1992). \\ 2. World Resources, 1990-1991 207, 209 (World Resources Institute UNEP Report, Oxford Univ. Press, Oxford, 1990). \\ 3. Fenton, R. Comparison of Coffee Cups (Winnipeg Packaging Project, Univ. Winnipeg, 1992). \\ 4. van Eijk, J. et al., Reusable Versus Disposable. A Comparison of the Environmental Impact of Polystyrene Paper/Cardboard, and Porcelain Crockery (Ministry of Housing, Physical Planning and Environment. Zoetermeer, The Netherlands, 1992).}

\section{HIV-1 infection of non-dividing cells}

SIR - Onco-retroviruses can productively infect only actively dividing cells ${ }^{1}$. In contrast, lentiviruses, including human immunodeficiency virus type 1 (HIV-1), can establish a productive infection in certain non-dividing cells ${ }^{2,3}$. Of particular importance to HIV-1 replication in vivo is the infection of non-dividing, terminally differentiated cells of the monocyte/ macrophage lineage such as microglia in the central nervous system ${ }^{4}$.

Bukrinsky et al. recently reported ${ }^{5}$ that a highly basic region of the HIV-1 matrix protein is responsible for the ability of HIV-1 to productively infect non-dividing cells (see Figs. 2 and 3 of ref. 5). This conclusion was based on the authors' observation that mutation of two adjacent lysine residues (matrix protein amino acids 25 and 26) to two threonine residues blocked infection of non-dividing cells by HIV-1. For these experiments, the authors used two types of non-dividing cells: $\gamma$-irradiated, $\mathrm{CD}^{+} \mathrm{HeLa}$ cells and aphidicolin-treated MT-4 T cells. Because they were able to direct bovine serum albumin, conjugated to the highly basic matrix protein domain, to the nucleus, they argued that this region of the HIV-1 matrix protein also targets the HIV-1 preintegration complex to the nucleus.

We have introduced a large number of mutations into the HIV-1 matrix protein, including the same two-amino-acid

\footnotetext{
1. Rubin, H. \& Temin, H. M. Virology 7, 75 91 (1959)

2. Haase, A. T. et al. Virology 119, 399-410 (1982).

3. Gartner, S. et al. Science 233, 215-219 (1986)

4. Koenig, S. etal. Science 233, 1089-1093 (1986)

5. Bukrinsky, M. I etal Nature 365, 666-669 (1993).

6. Yuan $X$. Yu, X. Lee, T. H. \& Essex, M.J.Virol.67, 6387-6394 (1993)
} 